\title{
Reattachment of a Fractured Crown Fragment of the Maxillary Central Incisor : a Case Report
}

\author{
Hariri El Mehdi ${ }^{*}$ and Fawzi Rachid ${ }^{2}$ \\ ${ }^{1}$ Department of Dentistry, Mohammed V University, Morocco \\ ${ }^{2}$ Department of Pediatric Dentistry, Mohammed V University, Morocco
}

Submission: : November 18, 2016; Published: December 13, 2016

*Corresponding author: Hariri El Mehdi, Faculty of dentistry, center of dental treatment and consultation, pediatric dentistry department, Mohamed V University, Morocco, PO: 6212 - Rabat Instituts Rabat Morocco,Tel: +212668607363; Email: haririelmehdi@gmail.com

\begin{abstract}
The Most Common traumatic dental injury is the uncomplicated crown fracture of the maxillary central incisor. Various reports have been presented about reattachment of the crown fragment, and literature reviews have cited that reattachment using an adhesive bonding agent is the best way of treating these injuries if the fragment is available, perfectlyadapted and properly stored. The present casereport describes an uncomplicated crown fracture of the maxillary right central incisor in a young patient who has 11 years old. The crown fragment was successfully re attached to the tooth using an acid-etchand adhesive bonding resin technique. After 1 years of following-up, the reattached fragment presents satisfying esthetics and excellent function.
\end{abstract}

Keywords: Uncomplicated crown fracture; Reattachment; Adhesive bonding resin

\section{Introduction}

The traumatic dental injuries are becoming more common, mainly because of an increase in the participation of children and teenagers in dangerous sports and activities [1]. Because of its position in the arch, maxillary incisors are the most common teeth involved in dental trauma, and it has been estimated that about one quarter of the population under the age of 18 sustain traumatic injury in the form of anterior crown fracture. It is a tragic experience for the patient who requires immediate attention, not only because of damage to the dentition but also because of psychologic effect of the trauma.

Aesthetical and functional rehabilitation of crown fractures is one of the greatest challenges for the dentist. When the coronal fragment is available and completely recovered intact, the reattachment of the original tooth fragment appears to be the most conservative treatment approach.

This case report describes the reattachment of a fractured crown fragment of the maxillary central incisor utilizing an ultraconservative preparation technique with one year of successfully following-up.

\section{Case Report}

11 year-old male patient presented to the Department of Pediatric Dentistry and Prevention of Rabat University, with a traumatic injury sustained when he had a bicycle accident 12 hours prior to his attendance. Past medical history was reviewed and there was no remarkable report. A complete history of the incident was taken.

The initial clinical examination did not reveal any soft tissue injury and no pathologic findings were noted during the investigation of the temporomandibular joint and potentially affected osseous structures. Intraoral examination revealed that right maxillary central crown was broken, without involving pulpal tissue. Intraoral periapical radiographic investigation confirms the clinical observation with an intact periodontal ligament space. The fragment was examined and checked from all sides. It was in good condition and it fit reasonably well with the remaining tooth structure. Based on the clinical and radiographic findings, a diagnosis of uncomplicated crown fracture was made.

After discussing with the patient and his father the available treatment options, we opted for the reattachment of the crown fragment by using an acid-etch and adhesive bonding resin technique. The fracture site and the fragment were acid etched with $37 \%$ phosphoric acid for 20s and rinsed thoroughly with air-water spray. Excess water was removed with a brief jet of air and the adhesive was applied to both surfaces. The fragment 
was positioned in its original place and light cured for 10 s from various directions. Finishing and polishing of the restoration were carried out and the occlusion was checked. The esthetic result was excellent and the repair was barely visible. A week later, the patient was called for a follow-up appointment. The patient reported that he had a little sensitivity to cold for about $12 \mathrm{~h}$ after the treatment, which disappeared after that.

One year later, the patient was called for control to check the vitality of the tooth. The tooth was vital and the reattached crown fragment presents satisfying esthetics and excellent function.

\section{Discussion}

The reattachment of natural tooth fragment is aesthetic and minimally invasive restorative alternative for the fractured anterior tooth. Compared with other restorative techniquessuch as flowable composite, dual cure orresin modified glass ionomers, the reattachment of fractured fragments can offer several advantages comprising preserve maximal natural tooth structure, better esthetics, less time consuming procedure and a positive emotional and social response from the patient for preservation of natural tooth structure. A large number of publications demonstrat a variety of techniques for this procedure, from simple reattachment depending solely on micromechanical bonding to various preparation techniques of the tooth and the fragment. A study carried out in 1999 by Worthington et al. compared the fracture resistance of reattachment fragments using simple reattachment, circumferential internal bevels and facial internal bevels together with lingual external bevels [2]. The results showed that in all groups the fracture resistance was restored up to one half that of intact controls for crown fractures and one third for root fractures [3]. This was in agreement with a study carried out in 1986 by Dean et al, who found that placement of a circumferential bevel does not increase retention [4]. A number of advantages have been cited in favor of tooth fragment reattachment. It is a conservative approach which does not preclude the use of other types of restorations later on should it fail. Among the earliest causes of Traumatic Dental Injuries described in the literature are increased overjet with protrusion and inadequate lip coverage [5,6]. Prevention of dental injuries is essential because of its frequency and consequences. It's obtained by studying their aetiology, their risk factors and by using intra-oral protection during the practice of a contact sport [7]. The treatment described in the present case report is reasonably simple, while restoring function and esthetics with a very conservative technique. The crown fragment was reattached by using an acid-etch with $37 \%$ phosphoric acid and adhesive bonding resin (3M) technique because the fragment was available, perfectly adapted and properly stored. In a recipient of milk. The storage environment is a factor of success of our technique with milk preference; it prevents desiccation of the crown fragment and provides better aesthetic results [8-18].

\section{Conclusion}

The reattachment of the intact fractured segment can be considered as an ultraconservative method for aesthetic rehabilitation. This is why it is necessary to educate the population to preserve the fractured segment and demand immediate dental treatment. The adhesive bonding resin technique can be used effectively to restore fractured teeth; presumably with sufficient strength but long-term follow up is essential to predict the durability of the tooth-adhesive-fragment complex and the vitality of the tooth (Figure 1-8).

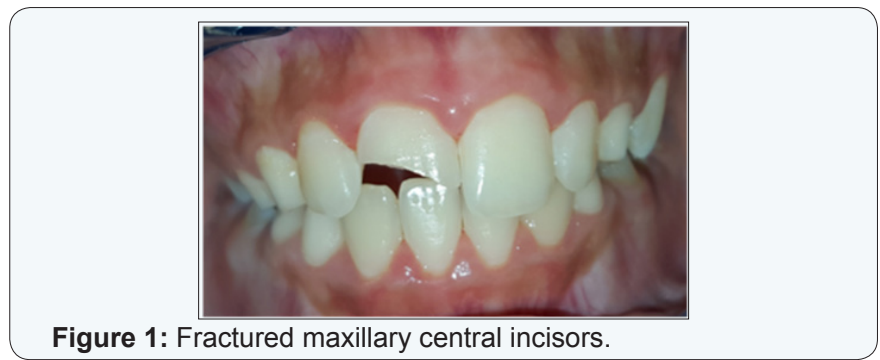

Figure 1: Fractured maxillary central incisors.

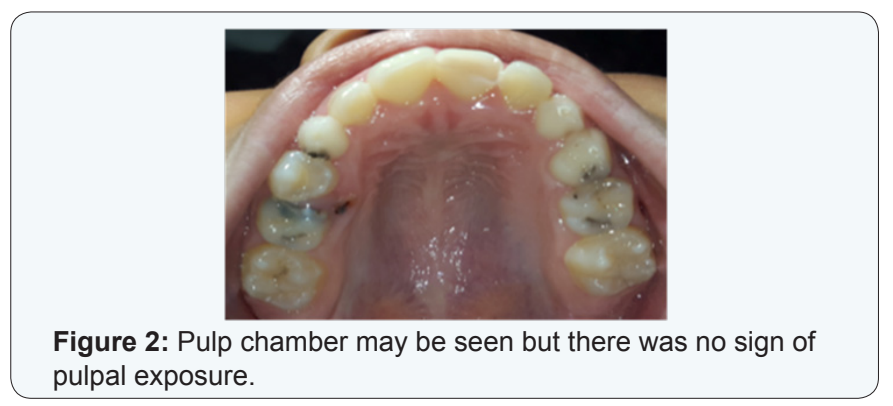
pulpal exposure.
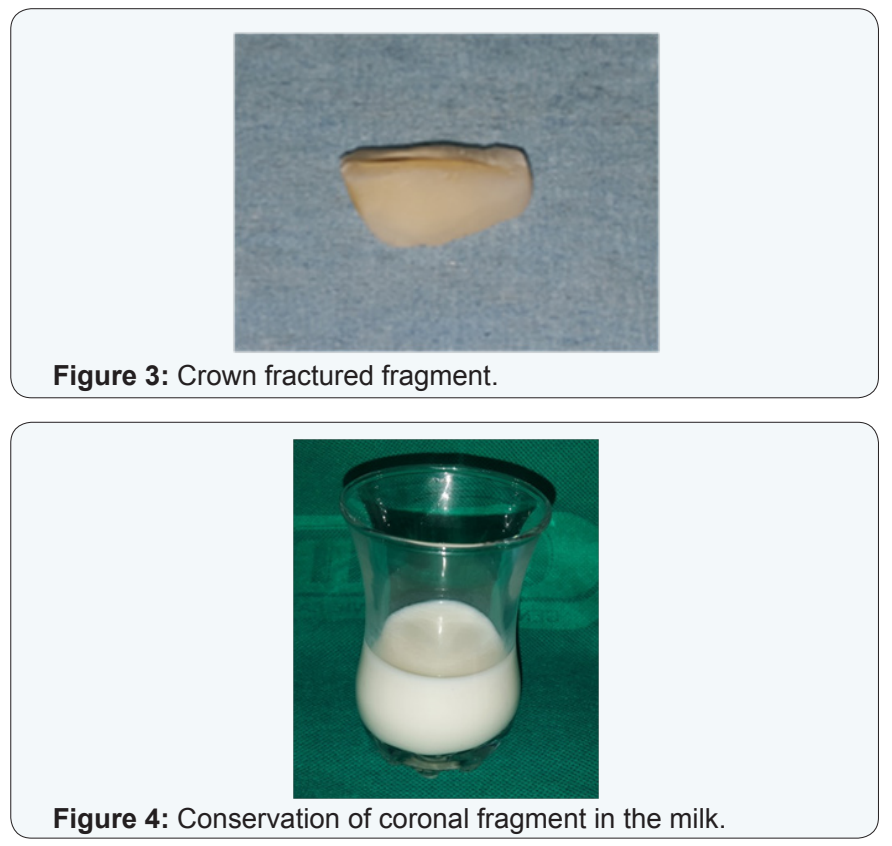

Figure 4: Conservation of coronal fragment in the milk.

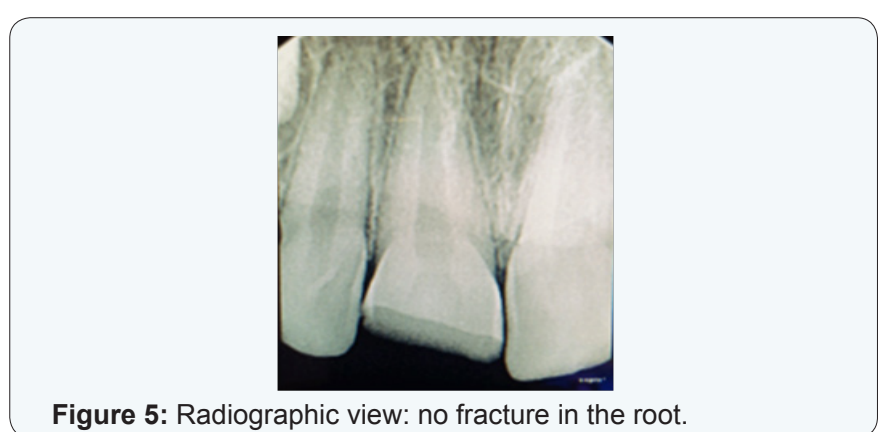

Figure 5: Radiographic view: no fracture in the root. 

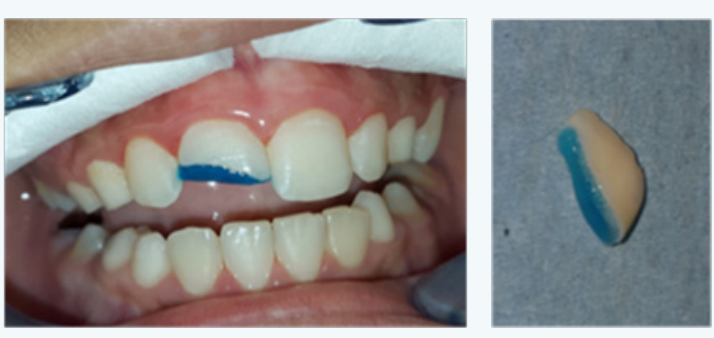

Figure 6: Radiographic view: no fracture in the root.
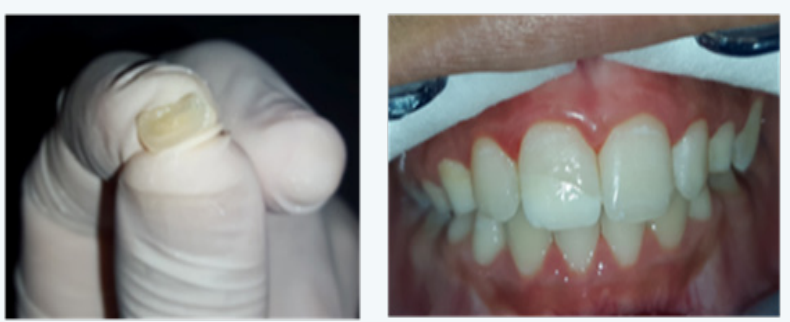

Figure 7: Reattachement with an adhesive bonding resine.
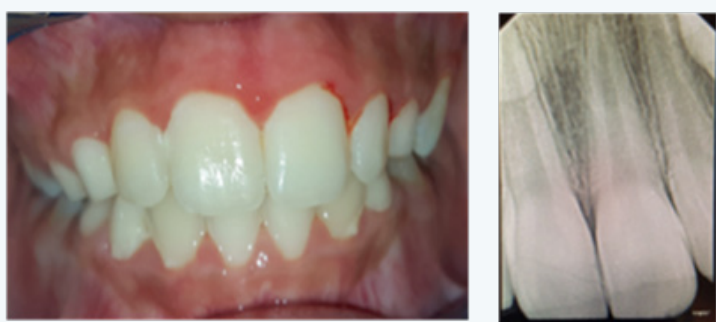

Figure 8: Toot at one year recall.

\section{References}

1. Marcenes W, Alessi ON, Traebert J (2000) Causes and prevalence of traumatic injuries to the permanent incisors of school children aged 12 years in Jaragua do Sul Brazil. Int Dent J 50(2): 87-92.

2. Worthington RB, Murchison DF, Vandewalle KS (1990) Incisal edge reattachment: the effect of preparation utilization and design. Quintessence Int 30(9): 637-643.

3. Baghdadi ZD (2000) Crown fractures: new concepts, materials and techniques. Compend Contin Educ Dent 21(10): 831- 836.

4. Dean JA, Avery DA, Swartz ML (1986) Attachment of anterior tooth fragments. Pediatr Dent 8(3): 139-143.
5. Shulman JD, Peterson J (2004) The association between incisor trauma and occlusal characteristics in individuals 8-50 years of age. Dent Traumatol 20(2): 67-74.

6. Nguyen QV, Bezemer PD, Habets L, Prahl-Andersen B (1999) A systematic review of the relationship between overjet size and traumatic dental injuries. Eur J Orthod 21(5): 503-515.

7. Glendor U, Marcenes W, Andreasen JO (2007) Classification, epidemiology and etiology. In: Andreasen JO, et al. (Eds.), Textbook and color atlas of traumatic injuries to the teeth, $\left(4^{\text {th }}\right.$ edn), Chapter 8 , Blackwell Munksgaard, University of Oxford, UK, pp. 228.

8. Munksgaard EC, Hojtved L, Jorgensen EH, Andreasen JO, Andreasen FM (1991) Enamel-dentin crown fractures bonded with various bonding agents. Endod Dent Traumatol 7(2): 73-77.

9. Murchison DF, Burke FJ, Worthington RB (1999) Incisal edge reattachment: indications for use and clinical technique. Br Dent J 186: 614-619.

10. Andreasen JO, Ravn JJ (1972) Epidemiology of traumatic dental injury to primary and permanent teeth in a Danish population sample. Int $]$ Oral Surg 1(5): 235-239.

11. Pagliarini A, Rubini R, Rea M, Campese M (2000) Crown fractures: effectiveness of current enamel-dentin adhesives in reattachment of fractured fragments. Quintessence Int 31(2):133-136.

12. Farik B, Munksgaard EC, Andreasen JO (2000) Impact strength of teeth restored by fragment-bonding. Endod Dent Traumatology 16(4): 151153.

13. Andreasen JO, Andreasen FM (1993) Textbook and colour atlas of traumatic injuries to the teeth. Blackwell Munksgaard, Copenhagen, Denmark, Europe.

14. Andreasen FM, Noren JG, Andreasen JO, Engelhardtsen S, LindhStromberg U (1995) Long-term survival of fragment bonding in the treatment of fractured crowns: a multicentre clinical study. Quintessence Int 26(10): 669-681.

15. Andreasen FM, Daugaard-Jensen J, Munksgaard EC (1991) Reinforcement of bonded crown fractured incisors with porcelain veneers. Endod Dent Traumatol 7(2): 78-83.

16. Lalloo R (2003) Risk factors for major injuries to the face and teeth. Dent Traumatol 19(1): 12-14.

17. Petti S, Tarsitani G (1996) Traumatic injuries to anterior teeth in Italian schoolchildren: prevalence and risk factors. Endod Dent Traumatol 12(6): 294-297.

18. Buonocore MG, Davila J (1973) Restoration of fractured anterior teeth with ultraviolet-light-polymerized bonding materials: a new technique. J Am Dent Assoc 86(6): 1349-1354.

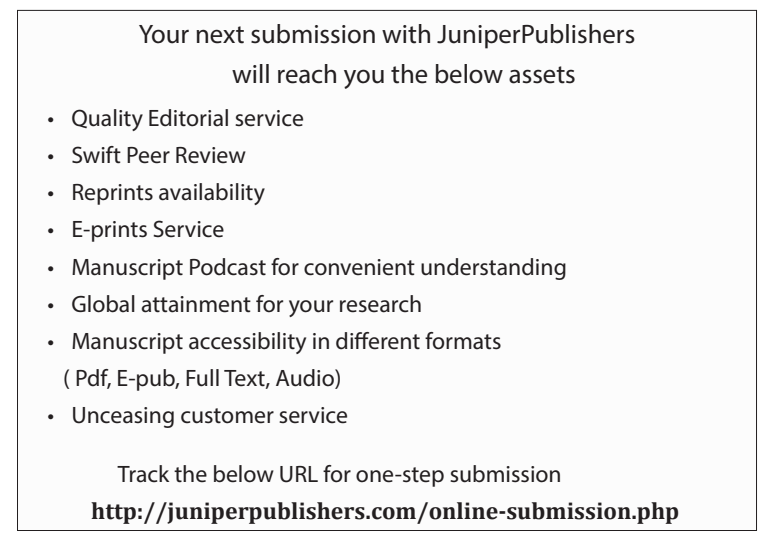

